\title{
Construção do marco regulatório da educação superior brasileira
}

\author{
Construction of the regulatory framework for brazilian higher education
}

\author{
Maria Carmo Lacerda Peixoto ${ }^{1}$ \\ Jane Cristina da Silva Pinto ${ }^{2}$
}

\begin{abstract}
Resumo: Este artigo analisa a construção do marco regulatório da educação superior brasileira, considerando as alterações ocorridas no Estado a partir da emergência da Nova Gestão Pública. Nessas circunstâncias, os atos normativos federais são produzidos por uma diversidade de órgãos e instâncias que atuam na regulação e avaliação da educação superior, tendo sido publicada uma multiplicidade de normas. Para o artigo foram identificados e analisados atos normativos publicados entre 2001 e 2019 , com o intuito de apreender o movimento de construção desse conjunto de normas e dos condicionantes que influenciaram na sua configuração atual. $O$ estudo revelou que sucessivas mudanças foram introduzidas nos processos de avaliação e regulação da educação superior por meio do quadro normativo e de seus diferentes instrumentos, demarcando os objetivos e interesses que envolvem a elaboração e a implementação de uma política pública.
\end{abstract}

Palavras-chave: Educação superior. Avaliação. Regulação. Marco regulatório. 
Abstract: This article analyzes the construction of the regulatory framework for Brazilian higher education, considering the changes promoted in the State with the emergence of the New Public Management. Federal normative acts are produced by a diversity of public organs and instances, that act in the regulation and evaluation higher education with a large number of rules being published. For the purpose of the article, normative acts published between 2001 and 2019 were identified and analyzed, aiming to apprehend the movement of construction of this set of norms and the conditions that influenced its current configuration. The study revealed successive changes introduced in the processes of evaluation and regulation of higher education, through the normative framework and its different instruments, demarcating objectives and interests involved in the elaboration and implementation of a public policy.

Keywords: Higher Education. Evaluation. Regulation. Regulatory framework.

${ }^{1}$ Universidade Federal de Minas Gerais | Programa de Pós-Graduação em Educação | Belo Horizonte| MG | Brasil. Contato: mcarmolp@gmail.com. ORCID: https://orcid.org/0000.0001.9960.707X

${ }^{2}$ Universidade de Brasília | Programa de Pós-Graduação em Educação | Brasília| DF | Brasil.

Contato: janecris1511@gmail.com. ORCID: https://orcid.org/0000.0003.1298.6199

- Recebido em: 30 de outubro de 2020

- Aprovado em: 12 de maio de 2021

DOI: http://dx.doi.org/10.1590/S1414-40772021000300011

Este é um artigo publicado em acesso aberto sob uma licença Creative Commons

https://creativecommons.org/licenses/by-nc/4.0/ 


\section{Introdução}

O advento da Nova Gestão Pública (NGP), com o objetivo de obter maior eficiência na administração pública, produziu alterações nos seus procedimentos, tendo também gerado mudanças nos modos de regulação social. Para Verger e Normand (2015), o desenvolvimento de reformas da NGP fragmenta os serviços públicos e promove uma gestão baseada em resultados. Afirmam os autores que o grande volume de recursos utilizados e de pessoal que trabalha no setor educacional torna o setor especialmente propenso à aplicação dessas reformas, alterando a concepção de governança das instituições educativas. Corroborando esta tese, Newman e Clarke (2012) aportam contribuições abordando o papel do gerencialismo como nova forma de poder no serviço público. Na educação superior brasileira, essas mudanças afetaram diretamente os processos de regulação e avaliação, sendo introduzidas sucessivas alterações no ordenamento de ambos os processos, de modo a constituir um conjunto de normas abrangente. Nesse conjunto ressalta a presença de interesses de diversas ordens, tanto visando especificamente a administração mais eficiente do sistema, quanto visando atender a interesses específicos oriundos de diversos segmentos que atuam na educação superior.

Este artigo é parte de pesquisa em andamento "Nova Gestão Pública e a reconfiguração da avaliação e regulação da educação superior", que conta com o apoio do Conselho Nacional de Desenvolvimento Científico e Tecnológico ( $\mathrm{CNPq}$ ). Tem por objetivo compreender e analisar a reconfiguração da avaliação e da regulação da educação superior na emergência da Nova Gestão Pública, frente ao novo perfil dos estudantes e ao seu desempenho nas avaliações do Exame Nacional de Desempenho de Estudantes (Enade) ${ }^{1}$. A pesquisa problematiza as práticas de gestão e acadêmicas relacionadas a este novo perfil considerando a implementação, a partir do início do século XXI, de um conjunto de políticas para a educação superior ${ }^{2}$, considerando a coexistência de modos institucionais de regulação e de políticas de gestão visando a conciliação dos interesses e perfis em disputa.

Para os objetivos da pesquisa, o estudo do conjunto de atos normativos publicados ao longo de um período permite compreender como os processos de regulação e avaliação vão sendo estruturados, evidenciando alterações e tendências na condução desses processos. Neste

\footnotetext{
${ }^{1} \mathrm{O}$ projeto conta com a participação de pesquisadores da Universidade de Brasília (UnB), da Universidade Federal de Minas Gerais (UFMG), da Universidade Estadual de Goiás (UEG), da Universidade Estadual do Maranhão (UEMA) e da Universidade Regional de Blumenau (FURB) e se constitui num dos eixos do projeto integrado "Políticas, gestão e direito à educação superior: novos modos de regulação e tendências em construção", conduzido por pesquisadores da Rede Universitas/Br.

${ }^{2}$ Entre outras políticas, ressalta no setor privado, o Programa Universidade para Todos (Prouni) e no setor público a ampliação de vagas do Programa de Apoio à Reestruturação e Expansão das Universidades Federais (Reuni) e a Lei 12.711 de 2012, que dispôs sobre o ingresso nessas IES, denominada Lei de Cotas.
} 
artigo, serão analisados os atos normativos referentes à avaliação e à regulação da educação superior brasileira, publicados entre 2001 e 2019. Foi reunido e tratado um conjunto de 631 normas composto por leis, decretos, portarias, portarias normativas, resoluções e instruções normativas. Como o foco da pesquisa é voltado para a educação superior oferecida na modalidade presencial, a educação a distância teve os atos normativos do período identificados e incluídos nesse conjunto, mas serão objeto apenas da análise mais geral dos dados.

O texto está organizado em três seções. Na primeira, são discutidas as articulações entre a avaliação e a regulação da educação superior brasileira nas duas primeiras décadas do século XXI. Na segunda seção, são analisados os dados relativos aos atos normativos publicados no período, considerando tendências evidenciadas na sua distribuição e a composição segundo o tipo de documento. Na terceira seção, os dados são analisados conforme categorias analíticas estabelecidas pela pesquisa. O artigo é encerrado com a apresentação de considerações finais a respeito do que foi discutido.

\section{Regulação, supervisão e avaliação da educação superior brasileira no século XXI}

Barroso (2005) ressalta a polissemia do conceito regulação, podendo ser entendido como ajuste de uma ação, como ação dos agentes econômicos na regulação de preços, como função essencial para o equilíbrio de qualquer sistema, como processo social de produção das regras do jogo, entre outros sentidos. Diante dessa diversidade, o autor busca sistematizar a regulação enquanto modo de coordenação dos sistemas educativos, afirmando que "a regulação é um processo constitutivo de qualquer sistema e tem por principal função assegurar o equilíbrio, a coerência, mas também a transformação desse mesmo sistema" (BARROSO, 2005, p. 733). Nesse modelo interpretativo, Barroso afirma que o processo de regulação compreende a produção de regras e, também, o reajustamento das ações dos atores em função dessas regras. Num sistema social complexo como o educacional, a regulação tem uma pluralidade de fontes, finalidades e modalidades, conforme a diversidade dos atores envolvidos, suas posições, seus interesses e estratégias. De acordo com o autor, a regulação do sistema educativo é um processo composto por uma heterogeneidade de elementos, em que o Estado não é a única fonte, havendo múltiplas regulações (meios de comunicação, pais, professores, etc.) a que o sistema está sujeito, as quais podem ser até contraditórias, o que compromete a previsibilidade do efeito das regulações institucionais partidas do Estado.

Nesses termos, nesse artigo se busca identificar e analisar como foi sendo construída a atual regulação da educação superior brasileira e a heterogeneidade de sua composição, em especial, na última década do século XXI. Nesse percurso, o ponto de partida são as 
regulamentações mais abrangentes da educação como a Constituição Federal e a Lei de Diretrizes e Bases da Educação Nacional, para chegar aos atos normativos mais específicos que foram sendo produzidos por organismos do Estado, que nesse caso é a fonte principal dos dados.

O inciso IX do artigo 24 da Constituição Federal de 1988 prescreve que compete à União, aos Estados e ao Distrito Federal legislar, concorrentemente, sobre a educação, cultura, ensino, desporto, ciência, tecnologia, pesquisa, desenvolvimento e inovação. No artigo 205, está prescrito que a educação é um direito social, dever do Estado e da família, visando ao pleno desenvolvimento da pessoa, bem como ao seu preparo para o exercício da cidadania e a qualificação para o trabalho (BRASIL, 1988). A concretização dessas prescrições depende de normatização adicional por meio de instrumentos legais específicos.

A regulamentação mais geral da educação brasileira se deu com a aprovação, em 20 de dezembro de 1996, da Lei no 9.394 de Diretrizes e Bases da Educação Nacional (LDB). Ela consolida como componente essencial da educação superior, a necessidade do estabelecimento de processos de avaliação visando à melhoria do ensino e à definição das ações de controle do sistema federal de ensino, por meio da expedição de atos regulatórios, tal como expresso no artigo 46: "a autorização e o reconhecimento de cursos, bem como o credenciamento de instituições de educação superior, terão prazos limitados, sendo renovados, periodicamente, após processo regular de avaliação" (BRASIL, 1996). Ratificando os termos da Constituição Federal, no inciso IX do artigo $9^{\circ}$, a LDB estabelece que cabe à União, autorizar, reconhecer, credenciar, supervisionar e avaliar os cursos das instituições de educação superior e os estabelecimentos do seu sistema de ensino (BRASIL, 1996).

Em complementação a essas normas gerais, inúmeros atos normativos federais relativos à regulação e à avaliação foram publicados: leis, decretos, instruções normativas, portarias, despachos, notas técnicas, etc. Nesses atos, entre outros aspectos, foram estabelecidos procedimentos para a regulação e a avaliação, divulgados indicadores de avaliação e definidos padrões decisórios.

Com o objetivo de analisar esses atos normativos, foram pesquisadas as páginas na internet da Secretaria de Regulação e Supervisão da Educação Superior (Seres), do Instituto Nacional de Estudos e Pesquisas Educacionais (INEP), da Imprensa Nacional (IN), do Conselho de Reitores das Universidades Brasileiras (CRUB) e da Associação Brasileira de Mantenedoras de Educação Superior (Abmes). A página do Conselho Nacional de Educação (CNE) embora não tenha sido incluída entre as fontes consultadas, um total de 18 resoluções da Câmara de Educação Superior foram identificadas nas páginas do INEP e da Abmes, integrando os documentos analisados. 
O levantamento dos documentos teve início em abril de 2019, abrangendo atos publicados entre os 1993 e 2020 e permanece em processo de atualização. A análise se concentra na identificação e caracterização da normatização geral da educação superior desse período, não tendo sido incluídos atos normativos específicos relacionados à autorização, reconhecimento e renovação de reconhecimento de cursos, assim como aqueles que regulamentam o credenciamento e o recredenciamento de instituições de educação superior.

Para os objetivos do artigo foi feito um recorte no total de atos, restringindo-se a análise aos atos publicados entre 2001 e 2019. A definição do período da análise se justifica porque foi nesse intervalo de tempo que se deu a sistematização, de forma mais ampla e volumosa, da regulação da educação superior no Brasil. Esta característica tem a ver com o processo de expansão de instituições e cursos públicos e privados, bem como a maior complexidade da conformação do sistema de educação superior, proporcionada pela introdução, entre outros, de procedimentos destinados à fusão e de formação de conglomerados educacionais na educação superior privada.

\subsection{Os documentos basilares da construção da regulação e avaliação da educação superior brasileira}

Até 2006, a organização do ensino superior e a avaliação de cursos e instituições de ensino superior eram regulamentadas pelo Decreto $n^{\circ} 3.860$ de 2001 (BRASIL, 2001), com foco sobre a "organização acadêmica das IES, a criação de cursos e de instituições e a avaliação de cursos e instituições de ensino superior”, esta última, organizada e executada pelo INEP.

Em 2004, na Lei 10.861 (BRASIL, 2004) que instituiu o Sinaes a avaliação e a regulação da educação superior foram estabelecidas de forma articulada, constituindo-se assim, num dos fundamentos da alteração que virá a seguir, com a publicação do Decreto no 5.773 de 2006 (BRASIL, 2006). Esse decreto marca o início do processo de sistematização e articulação da regulação e da avaliação, porque dispôs sobre o "exercício das funções de regulação, supervisão e avaliação das IES e dos cursos superiores de graduação e sequenciais no sistema federal de ensino". São abordados o credenciamento e recredenciamento de instituições, o credenciamento de campus fora de sede, a alteração de mantença, a oferta de educação a distância e a autorização, reconhecimento e renovação de reconhecimento de cursos. O decreto aborda, ainda, a supervisão e seus processos e a avaliação, estruturada com base no Sinaes e operacionalizada pelo INEP, segundo diretrizes da Comissão Nacional de Avaliação da Educação Superior (Conaes). 
Esse processo de estruturação vai ter continuidade em 2007, com a publicação da Portaria Normativa $n^{\circ} 40$. Esse documento institui o e-MEC, sistema eletrônico de fluxo de trabalho e gerenciamento de informações relativas aos processos de regulação da educação superior no SFE. Trata ainda dos processos de credenciamento e recredenciamento de IES e autorização de curso; da tramitação do processo de avaliação no INEP; das comissões de avaliadores; do processo de regulação no CNE; da autorização, reconhecimento e renovação de reconhecimento de curso; do ciclo avaliativo; do credenciamento, autorização e reconhecimento da oferta $\mathrm{EaD}$.

A Portaria $\mathrm{n}^{\mathrm{o}} 40$ foi republicada e consolidada em 2010, tendo por objetivo simplificar, racionalizar e abreviar o trâmite dos processos relacionados no Decreto $\mathrm{n}^{\circ} 5.773$ de 2006 e "utilizando, ao máximo, as possibilidades oferecidas pela tecnologia da informação" (BRASIL, 2010). Na Portaria 40 de 2010 novos itens foram incluídos: possibilidade de dispensa da avaliação in loco para a autorização de cursos presenciais conforme Conceito Institucional (CI) e Índice Geral de Cursos (IGC) mais recentes da IES; duração da avaliação in loco; ingresso e exclusão do Banco de Avaliadores (BASis) do Sinaes; instrumentos de avaliação; procedimentos relativos ao Enade; possibilidade de prorrogação do recredenciamento ou da renovação de reconhecimento com Conceito Preliminar de Curso (CPC) ou IGC satisfatórios, ato de autorização válido e ausência de medida de supervisão. A nova portaria 40 instituiu também o cadastro eletrônico e-MEC mantido pelo MEC e base de dados oficial e única de informações relativas às IES e cursos. Nesse cadastro deveriam ser também inseridos o Plano de Desenvolvimento Institucional (PDI), o Plano Pedagógico de Curso (PPC) e o relatório de autoavaliação da IES. A portaria determinou ainda a indicação pelas IES de um Procurador Educacional Institucional (PI), responsável pelas informações inseridas no cadastro e pelos processos regulatórios e de avaliação e instituiu o Cadastro Nacional de Docentes, sob a responsabilidade das instituições e estabeleceu normas para a coleta de informações sobre os estudantes pelo Censo da Educação Superior.

Mais recentemente, o Decreto $n^{\circ} 9.235$ de 2017 instituiu novo conjunto de normas para a educação superior. Este documento dispõe sobre o exercício das funções de regulação, supervisão e avaliação das IES e dos cursos superiores e de pós-graduação no SFE (BRASIL, 2017a). Revoga o Decreto 5.773, exclui os cursos sequenciais ${ }^{3}$, incorpora os cursos de pós-

\footnotetext{
${ }^{3}$ A Resolução CES/CNE no 01, de 22 de maio de 2017, que dispõe sobre os cursos sequenciais, determinou, no art. $3^{\circ}$, que os cursos sequenciais de formação específica regularmente oferecidos pelas Instituições de Educação Superior teriam a oferta encerrada em definitivo, no prazo máximo de dois anos, contados a partir da sua publicação.
} 
graduação lato sensu aos processos de regulação, supervisão e avaliação, bem como aspectos da Portaria 40 de 2010 concernentes à flexibilização e à simplificação de atos regulatórios e de procedimentos avaliativos.

Nessas circunstâncias, os documentos legais introduzidos a partir de 2006 evidenciam o maior grau complexidade adquirido pelos processos de regulação e avaliação da educação superior. Essa complexidade pode ser atribuída à ampliação da abrangência do sistema, com a configuração adquirida pelo sistema privado, a partir do final da década de 1990 e pela diversificação dos processos avaliativos, a partir do Sinaes.

A gestão desse processo de regulação levou à reestruturação interna do MEC em 2011, quando foi criada a Secretaria de Regulação e Supervisão da Educação Superior (Seres) pelo Decreto $\mathrm{n}^{\mathrm{o}}$ 7.480, de 17 de abril de 2011. Esta secretaria vai assumir as atividades de regulação e supervisão da educação superior, antes dispersas entre outras três secretarias: a Secretaria de Ensino Superior (SESu), a Secretaria de Educação Profissional e Tecnológica (Setec) e a Secretaria de Educação a Distância (Seed). A Seres se torna, assim, a principal responsável pela formulação de políticas para a regulação e supervisão de cursos e instituições de educação superior públicas e privadas do Sistema Federal de Ensino ${ }^{4}$, consolidando a regulação da educação superior como atividade integrante do organograma do MEC.

A seguir, serão analisados os documentos identificados pela pesquisa, considerando sua distribuição ao longo do período e a composição dos atos regulatórios por tipo de documento publicado. Nessa análise está também incluída a discussão dos dados conforme a composição por categorias analíticas.

\section{Distribuição dos atos normativos}

Os documentos pesquisados abrangem o período correspondente aos anos de 2001 a 2019, tendo sido identificados 631 atos normativos. Esses atos apresentaram distribuição irregular ao longo do período, como mostra o gráfico 1.

\footnotetext{
${ }^{4}$ Nos termos do art. 16 da LDB, o Sistema Federal de Ensino compreende: as instituições de ensino mantidas pela União; as instituições de educação superior mantidas pela iniciativa privada; e, os órgãos federais de educação. No art. $2^{\circ}$ do Decreto ${ }^{\circ} 9.235$ de 15 de dezembro de 2017, foi estabelecido que além, das IES mantidas pela iniciativa privada, as IES criadas pelo Poder Público estadual, distrital ou municipal mantidas por pessoas jurídicas de direito privado e as IES qualificadas como instituições comunitárias, também estão sujeitas ao sistema federal de ensino.
} 
Gráfico 1 - Distribuição dos atos normativos segundo o ano de publicação (2001-2019)

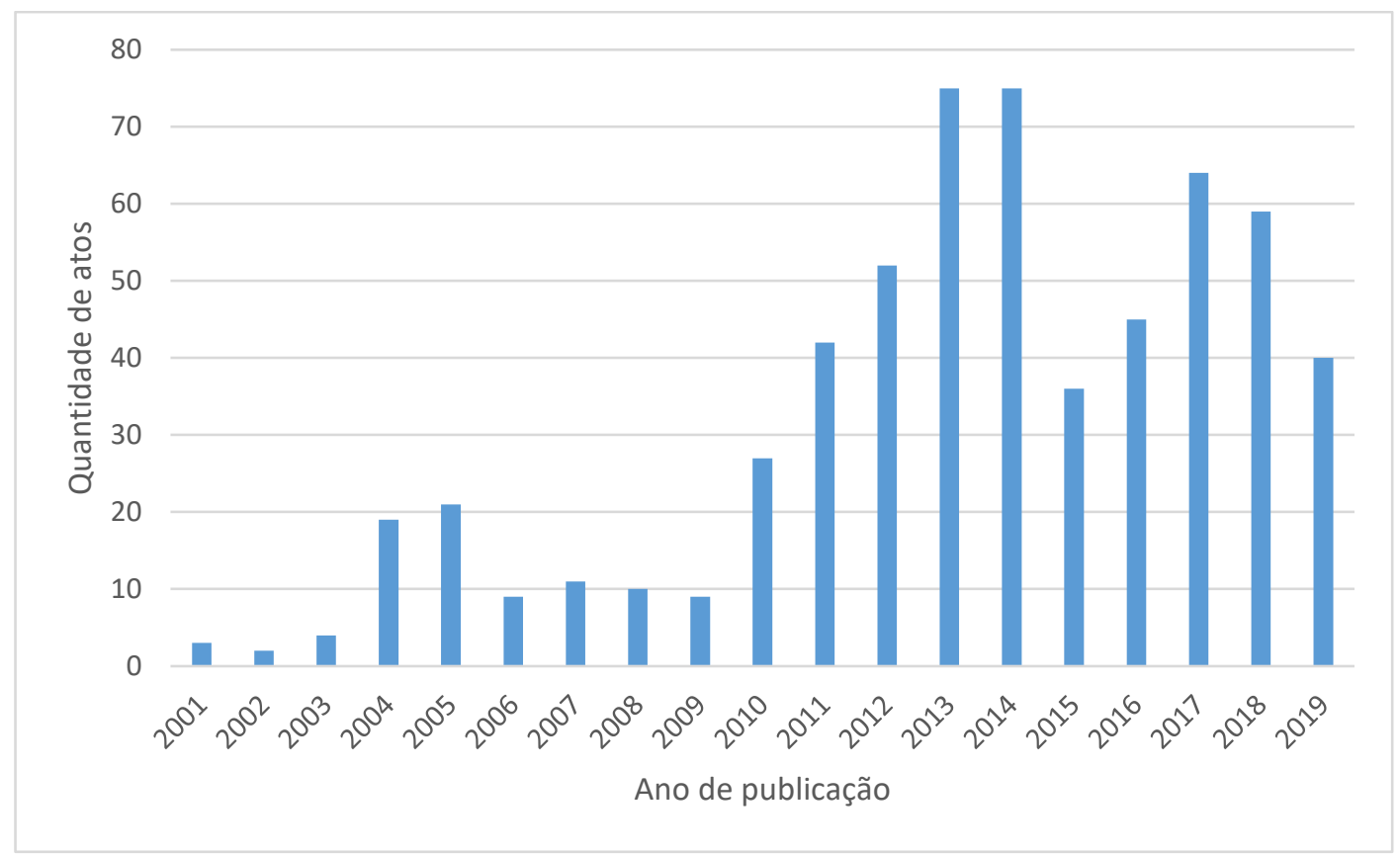

Fonte: Dados consolidados pela pesquisa.

Até 2009, a publicação dos documentos foi feita em pequena quantidade, em relação ao que se verifica a partir de 2010. Entre 2006 e 2009, o número de atos publicado foi superior à dos três anos iniciais da série. O aumento ocorrido nos anos 2004 e 2005 pode ser considerado como pontual, estando associado à instituição do Sinaes em 2004, pois 50\% dos atos normativos publicados nesses dois anos teve a avaliação por tema. Esse fato é um marco também do início da estruturação, de forma mais abrangente, da avaliação e da regulação da educação superior, dada a articulação, como observado, dessas duas dimensões prescrita na Lei nº 10.861 de 2004 . Nesse sentido, pode-se considerar que a regularidade da distribuição das publicações entre 2006 e 2009 é um indicador do início de um processo mais sistemático de estruturação da regulação da educação superior brasileira, o que se comentará adiante mais detalhadamente.

A partir de 2010, configura-se uma tendência de ampliação do processo regulatório da educação superior. Destacam-se os anos de 2013 e 2014, ressaltando-se, ainda, os anos de 2017 e 2019, embora apresentem quantidade inferior de publicações em relação aos dois anos anteriores.

Essa ampliação deve ser associada a políticas implementadas no governo Lula da Silva, que desempenharam papel importante na expansão da educação superior privada como o Programa Universidade para Todos (Prouni), em 2004 e o Fundo de Financiamento Estudantil (FIES), em 2001, originando inúmeras portarias. A ampliação de vagas do Programa de Apoio 
à Reestruturação e Expansão das Universidades Federais (Reuni) em 2007, bem como a criação de novas instituições federais e a aprovação da Lei $n^{\circ} 12.711$, de 2012, a lei de cotas, no entanto, foram políticas implementadas na educação superior federal no período, mas, dadas suas características, não tiveram o mesmo impacto sobre o número de atos regulatórios. Devem ser consideradas ainda a criação e implantação de novos programas como o Mais Médicos no governo Dilma Rousseff, cujo desenvolvimento envolveu a formação de médicos nos cursos de graduação, por meio da abertura de cursos de medicina e a ampliação de vagas nessa área nas instituições federais e em IES privadas, que demandaram a elaboração de normas. Com relação aos anos de 2017 e 2018, a maior quantidade de atos publicados deve ser atribuída à revisão normativa implementada no governo Michel Temer, com o objetivo de "desburocratizar e premiar instituições pela qualidade" e "tornar mais ágil o processo de supervisão, avaliação e regulação da educação superior" (BRASIL, 2017c). Esse movimento de revisão das normas teve a ver com a mudança de direção das políticas promovida por esse governo na educação superior, visando principalmente atender às demandas do segmento privado.

Mais importante do que o papel desempenhado pelas novas políticas, contudo, a maior quantidade de documentos publicados nos anos de 2013 e 2014 está relacionada principalmente à atuação da Seres na estruturação da regulação e a supervisão da educação superior. Após sua criação, a secretaria precisou criar normas para dar andamento à grande quantidade de processos acumulados e aplicou muitas medidas de supervisão, o que contribuiu para a expansão mostrada no gráfico. Tendo em vista a dimensão assumida pelo grande número de processos em relação ao de servidores da Seres e a intenção de ampliar o raio de ação da secretaria, em 2012 foi feita proposta, transformada em projeto de lei, para criar o Instituto Nacional de Supervisão e Avaliação da Educação Superior (Insaes), com a finalidade de "supervisionar e avaliar instituições de educação superior e cursos de educação superior no sistema federal de ensino, e certificar entidades beneficentes que atuem na área de educação superior e básica" (BRASIL, 2012). No projeto de lei, estão previstas a estruturação do órgão e plano de carreira envolvendo 350 cargos de Especialista em Avaliação e Supervisão da Educação Superior, 150 de Analista Administrativo e 50 de Técnico Administrativo. O projeto de lei tramita na Câmara dos Deputados desde 31 de agosto de 2012, designado como PL 4.372/2012 e, até 24 de outubro 2019, ainda constava como projeto em exame pela Comissão de Constituição e Justiça e Cidadania. 


\subsection{Composição dos atos normativos por tipo de documento}

Os atos normativos se desdobram em leis, decretos, despachos, instruções normativas, notas técnicas, portarias, portarias normativas e resolução. Analisar sua composição por tipo de documento se constitui em passo importante para o estudo da construção do marco normativo, na medida em que demonstra quais foram os procedimentos utilizados de forma predominante, alguns deles, inclusive, buscando dar mais agilidade aos processos de regulação.

Como mencionado, apesar de a educação superior a distância (EaD) não ser objeto da pesquisa, foram identificados os atos a ela relacionados, em número reduzido frente ao total de documentos. São 28 atos normativos no período estudado, sendo uma lei, três decretos, sete portarias, cinco portarias normativas, três resoluções, uma instrução normativa, quatro notas técnicas e quatro despachos. Esses documentos são aqui considerados apenas para a análise inicial da distribuição dos atos segundo o tipo, no quadro a seguir.

A composição dos atos normativos do período 2001-2019, de acordo com o tipo de documento publicado, é mostrada no quadro 1.

Quadro 1 - Distribuição dos atos segundo o tipo (2001-2019)

\begin{tabular}{|l|c|}
\hline \multicolumn{1}{|c|}{ Tipo de ato normativo } & Quantidade \\
\hline Decreto & 24 \\
\hline Despacho & 42 \\
\hline Instrução Normativa & 19 \\
\hline Lei & 24 \\
\hline Nota Técnica & 66 \\
\hline Portaria & 247 \\
\hline Portaria Normativa & 183 \\
\hline Resolução & 26 \\
\hline Total & $\mathbf{6 3 1}$ \\
\hline
\end{tabular}

Fonte: Dados consolidados pela pesquisa.

Em termos quantitativos, os documentos estão concentrados em portarias e portarias normativas. As portarias são documentos editados por uma ou mais autoridades singulares do Poder Executivo Federal, ministros ou secretários, conforme previsto no Decreto $\mathrm{n}^{\circ} 10.139$, de 28 de novembro de 2019, que dispõe sobre a revisão e a consolidação dos atos normativos inferiores a decreto (BRASIL, 2019). A denominação portaria normativa, contudo, não se encontra descrita no decreto mencionado acima. Juntos, esses dois tipos de atos corresponderam a $68 \%$ do total identificado ${ }^{5}$.

\footnotetext{
${ }^{5}$ De acordo com o verbete Portaria (2020), da Enciclopédia Jurídica, portaria é um documento resultante de ato administrativo de qualquer autoridade pública, contendo instruções a respeito da praticabilidade de determinada
} 
Cabe observar ainda a importância das notas técnicas, correspondentes a $10 \%$ do total. As notas técnicas são documentos elaborados por técnicos especializados dos diversos órgãos e destinam-se, em tese, a possibilitar um posicionamento mais ágil do Poder Público, dado que, pelo seu caráter mais específico, não demandam tratamento hierárquico em nível superior, como ocorre com a portaria. Têm sido utilizadas, por exemplo, para explicitar metodologias de avaliação e definir padrões decisórios quanto a determinados aspectos da regulação e supervisão de cursos e instituiçõos.

Esses três tipos de documentos tiveram distribuição bastante irregular ao longo do período, como mostra o gráfico 2.

\section{Gráfico 2 - Distribuição de Portarias, Portarias Normativas e Notas Técnicas, segundo o ano de} publicação (2001-2019)

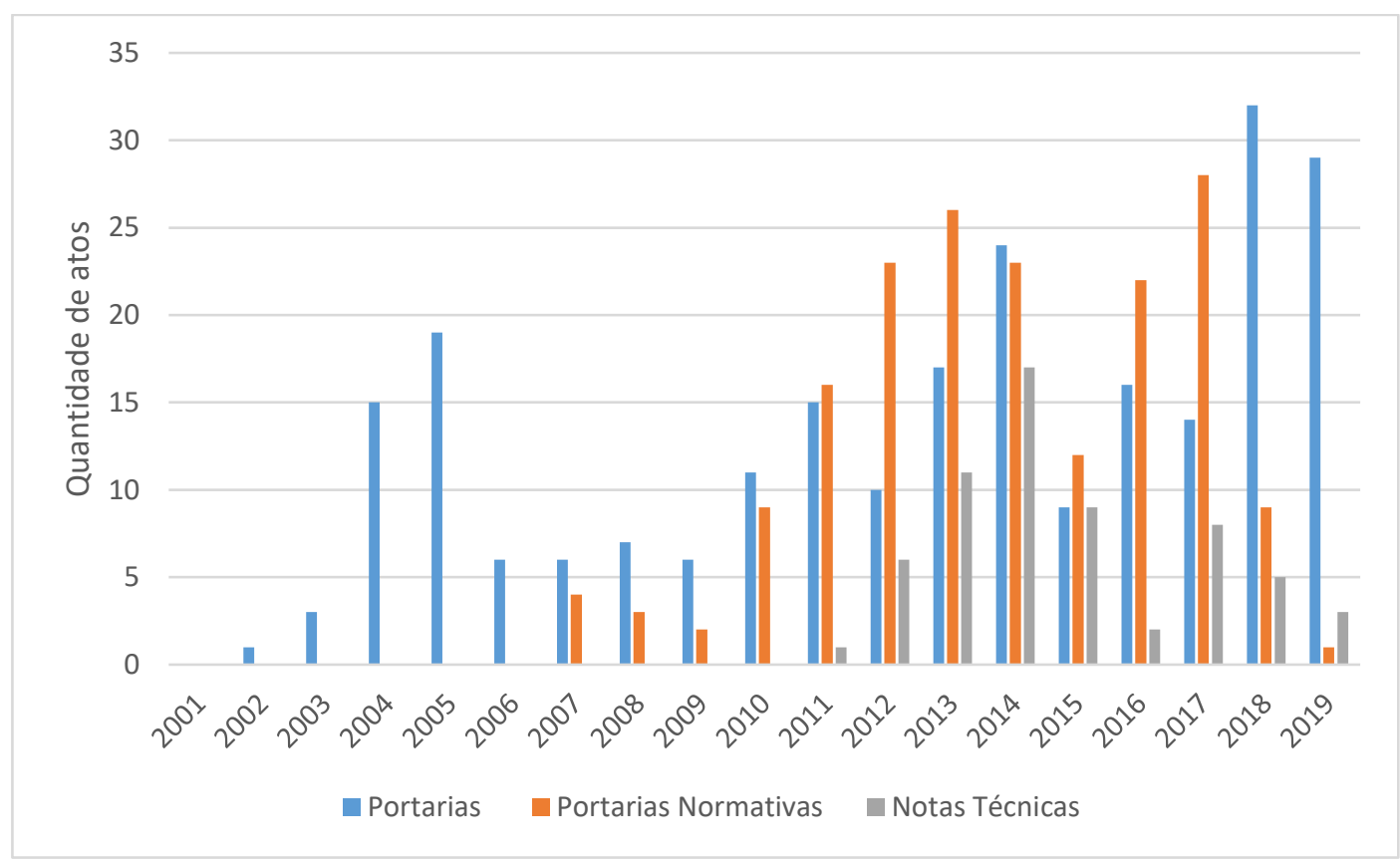

Fonte: Dados consolidados pela pesquisa.

A publicação das 240 portarias se distribuiu ao longo de todo o período, sendo a maior quantidade nos anos de 2018 e 2019, embora número expressivo delas tenha sido emitido também em 2014, correspondendo a 41\% do total das publicadas. As 178 portarias normativas começaram a ser editadas em 2007, em proporção mais elevada nos anos de 2012, 2013, 2014, 2016 e 2017, correspondendo esse período a 66\% do seu total. As 62 notas técnicas começaram

lei ou regulamento. Essa denominação é aplicada, também, para determinar normas gerais para a execução de determinado serviço, para nomeações, demissões, punições ou qualquer outra determinação. Nesse sentido, é possível considerar a segunda conceituação aplicável a portaria normativa. 
a ser publicadas apenas em 2011, sua produção se acentuando um pouco em 2013 e atingindo o nível mais elevado em 2014. Nesses dois anos foram emitidas $45 \%$ do total de notas técnicas, ou seja, por um curto período, a urgência em dar andamento aos processos regulatórios levou à publicação, em 2014, desse ato de menor rigor hierárquico em percentual equiparável ao das portarias e portarias normativas emitidas ao longo do período analisado. Após 2014, no entanto, a publicação das notas técnicas continua presente, mas em tendência decrescente, talvez por estarem já mais bem estruturados os procedimentos regulatórios.

\section{Composição dos atos normativos por categorias}

Para a análise dos documentos, foram estabelecidas quatro categorias, considerando as temáticas da educação superior abordadas pelos atos normativos. Os documentos foram categorizados conforme se relacionam mais diretamente à regulação, à avaliação e à supervisão, sendo incluída também uma categoria de caráter mais abrangente, denominada educação superior.

O gráfico 3 mostra a distribuição dos atos normativos por categoria.

Gráfico 3 - Distribuição dos atos normativos segundo a categoria

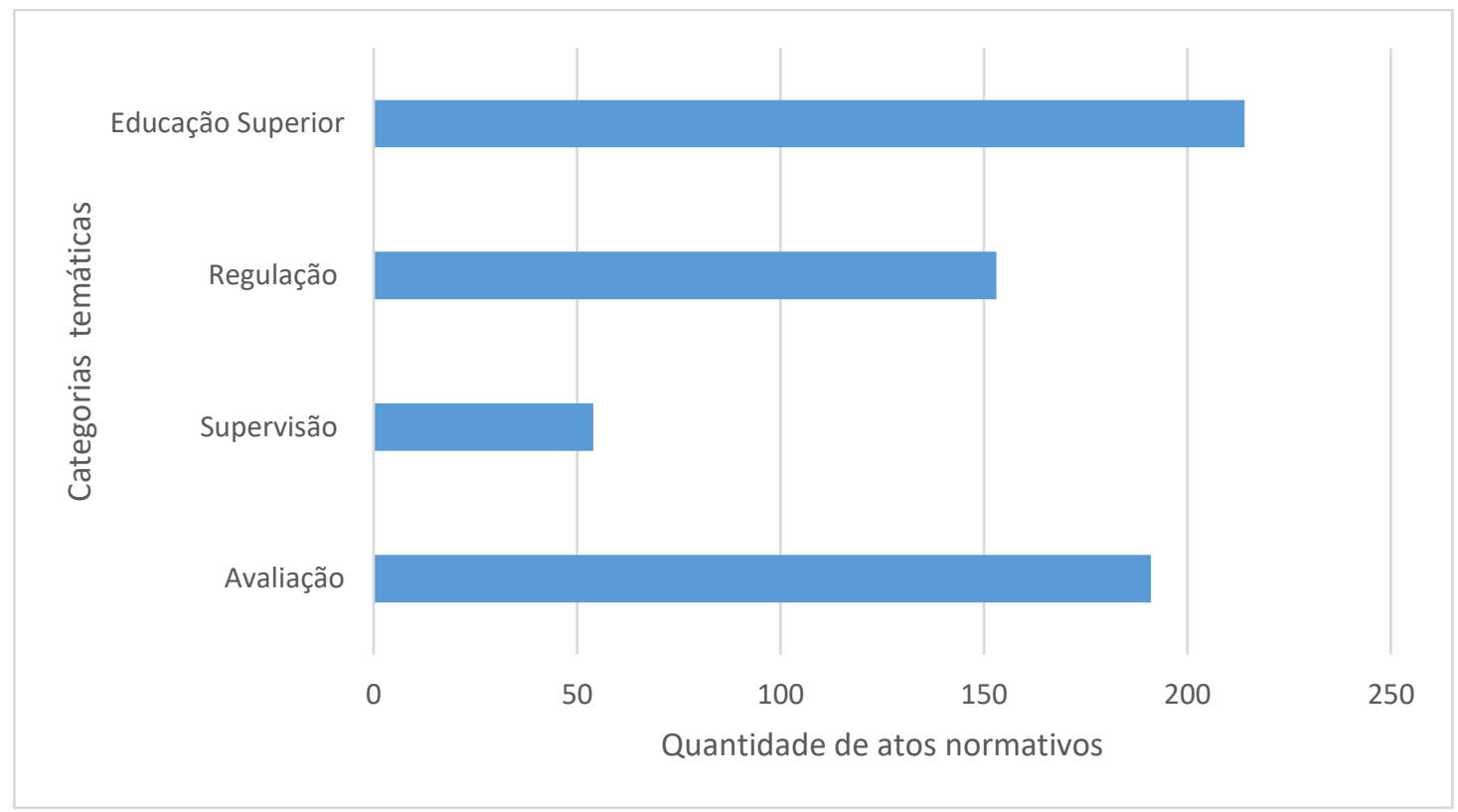

Fonte: Dados consolidados pela pesquisa.

O gráfico mostra uma distribuição desigual dos documentos. Dadas suas características, na categoria educação superior está contido o maior volume de atos, vindo a da avaliação a seguir. 
Os atos normativos classificados na categoria Educação Superior abordam ações de caráter mais geral. A composição da categoria por tipo de documento é mostrada no quadro 2.

Quadro 2 - Composição da categoria Educação Superior por tip
\begin{tabular}{|l|c|}
\hline \multicolumn{1}{|c|}{ Tipo de documento } & Quantidade \\
\hline Lei & 21 \\
\hline Decreto & 12 \\
\hline Portaria & 62 \\
\hline Portaria Normativa & 107 \\
\hline Instrução Normativa & 02 \\
\hline Nota Técnica & 05 \\
\hline Despacho & 05 \\
\hline Total & $\mathbf{2 1 4}$ \\
\hline
\end{tabular}

Fonte: Dados consolidados pela pesquisa.

Entre os temas abordados nesta categoria encontram-se, por exemplo, diretrizes curriculares, Programa Mais Médicos, Universidade Aberta do Brasil, Sistema de Seleção Unificada - SiSU, Certificado de Entidades Beneficentes de Assistência Social (Cebas), Programa Universidade para Todos (ProUni), Fundo de Financiamento Estudantil (FIES), entre outros. É nesta categoria que se encontra o maior número de leis, a exemplo da Lei de Cotas e as dos dois Planos Nacionais da Educação.

A quantidade de portarias e portarias normativas é bem elevada neste segmento, correspondendo, juntas, a 79\% do total. Dentre os temas abordados nelas encontram-se atos referentes aos programas de financiamento da educação superior, correspondendo juntos FIES e ProUni a 59\% das portarias nesta categoria. Nelas são abordados, entre outros aspectos, procedimentos para contratação de financiamentos, processos seletivos e o tratamento dado a bolsas remanescentes.

Alguns atos normativos abrangem temas tanto da avaliação quanto da regulação, como é o caso da Lei $n^{\circ} 10.861 / 2014$, que instituiu o Sinaes e articulou a avaliação e a regulação da educação superior. O mesmo ocorre com decretos como o 3.860, de 09 de julho de 2001, o 5.773, de 09 de maio de 200,6 e o 9.235, de 15 de dezembro de 2017, que abordam o exercício das funções de regulação, supervisão e avaliação de instituições de educação superior e de seus cursos. Por essa razão, eles foram incluídos tanto numa quanto na outra categoria, razão pela qual as somas dos totais das categorias Regulação e Avaliação não vão conferir com o que consta no quadro 1.

O quadro 3 apresenta a composição dos atos na categoria Regulação por tipo de documentos. 


\section{Quadro 3 - Composição da categoria Regulação por tipo de documento}

\begin{tabular}{|l|c|}
\hline \multicolumn{1}{|c|}{ Tipo de documento } & Quantidade \\
\hline Lei & 01 \\
\hline Decreto & 08 \\
\hline Portaria & 35 \\
\hline Portaria Normativa & 40 \\
\hline Resolução & 21 \\
\hline Instrução Normativa & 12 \\
\hline Nota Técnica & 22 \\
\hline Despacho & 14 \\
\hline Total & $\mathbf{1 5 3}$ \\
\hline Fonte: Dados consolidados pela pesquisa \\
\hline
\end{tabular}

Nessa categoria, estão incluídos temas relacionados a procedimentos gerais da regulação, tais como abertura de calendário para protocolo de processos, adoção de padrões decisórios, adoção de critérios para dispensa de avaliação in loco. Estão incluídos, também, atos relativos a processos destinados a estabelecer procedimentos para autorização, reconhecimento e renovação de reconhecimento de cursos, credenciamento e recredenciamento institucional, transferência de mantença e unificação de mantidas, entre outros.

Os documentos da categoria regulação se compõem, em sua maioria, de portarias, portarias normativas, notas técnicas e resoluções. Os dois primeiros tipos de atos representam, juntos, $49 \%$ do total da categoria e destinam-se ao estabelecimento de normas e procedimentos para a instituição de calendários, comissões e grupos de trabalho, bem como dispõem sobre atos regulatórios específicos para autorização de cursos e credenciamento de instituições de educação superior, entre outros. As notas técnicas correspondem a 14\% do total, destinando-se, em sua maior parte, à divulgação de padrões decisórios e à sistematização de procedimentos adotados em relação aos processos regulatórios. As resoluções foram emitidas em sua maior parte pelo CNE, havendo ainda resoluções da Seres, do INEP e da Conaes, abordando temas como diretrizes curriculares, credenciamento e recredenciamento de IES, revalidação de diplomas, além de delegações de competência do CNE para secretarias do MEC.

Além dessas, há resoluções procedentes de organismos não governamentais que são os conselhos profissionais, que abordam temas relativos ao exercício profissional, como é o caso da restrição à inscrição e registro de egressos no Conselho Federal de Odontologia de cursos realizados integralmente na modalidade a distância e da regulação das atividades de médicos estrangeiros no Brasil e de médicos brasileiros formados no exterior. A legislação vigente prevê também a manifestação do Conselho Federal da Ordem dos Advogados do Brasil (OAB) e do 
Conselho Nacional de Saúde (CNS) nos processos de autorização de cursos de Direito, Medicina, Odontologia, Psicologia e Enfermagem, inclusive quando ofertados por instituições dotadas de autonomia, como universidades e centros universitários. Esse tipo de participação no processo regulatório remete à regulação intensiva em conhecimento e à multirregulação das políticas da educação superior, mencionados anteriormente segundo Barroso e Carvalho (2011) e Barroso (2005), respectivamente.

Voltada para o controle do cumprimento do prescrito nos atos normativos da educação superior, a Supervisão é parte integrante do processo regulatório. O quadro 4 apresenta a composição dos atos nesta categoria.

\section{Quadro 4- Composição da categoria Supervisão por tipo de documento}

\begin{tabular}{|l|c|}
\hline \multicolumn{1}{|c|}{ Tipo de documento } & Quantidade \\
\hline Portaria & 13 \\
\hline Portaria Normativa & 7 \\
\hline Nota Técnica & 15 \\
\hline Despacho & 19 \\
\hline Total & $\mathbf{5 4}$ \\
\hline
\end{tabular}

Fonte: Dados consolidados pela pesquisa

A quantidade de documentos nesta categoria é mais restrita, sendo encontrados, entre outros, atos relativos a medidas cautelares aplicadas a instituições e cursos de graduação, além de procedimentos a serem adotados em virtude de resultados insatisfatórios nos processos avaliativos e relativos à política de transferência assistida nos casos de descredenciamento de instituições. O despacho foi o ato emitido com maior frequência, sendo responsável por 35\% dos documentos nesta categoria. Esse documento diz respeito à manifestação de autoridade administrativa em um processo administrativo, podendo ter caráter decisório ou de encaminhamento de expediente (BRASIL, 2017b) tendo, geralmente, caráter decisório e se destina à aplicação ou à revogação de sanções a instituições e cursos por ocasião da instauração de processos de supervisão. As notas técnicas e as portarias se aproximam da proporção dos despachos, constituindo $28 \%$ e $24 \%$, respectivamente, da composição desta categoria. 
O quadro 5 traz a composição dos documentos na categoria Avaliação.

\section{Quadro 5 - Composição da categoria Avaliação por tipo de documento}

\begin{tabular}{|l|c|}
\hline \multicolumn{1}{|c|}{ Tipo de documento } & Quantidade \\
\hline Lei & 02 \\
\hline Decreto & 06 \\
\hline Portaria & 131 \\
\hline Portaria Normativa & 25 \\
\hline Resolução & 02 \\
\hline Instrução Normativa & 04 \\
\hline Nota Técnica & 21 \\
\hline Total & $\mathbf{1 9 1}$ \\
\hline
\end{tabular}

Fonte: Dados consolidados pela pesquisa

Na categoria avaliação, os atos normativos abordam instrumentos de avaliação, áreas e cursos a serem submetidos anualmente aos processos avaliativos e a publicidade a ser dada aos seus resultados. As portarias e portarias normativas estão em maior proporção correspondendo, juntas, a $81 \%$ do total. Nelas são divulgados calendários para realização do Enade, metodologias e cálculos dos indicadores adotados, instituição de comissões de assessoramento, etc. Embora em proporção menor (11\%), as notas técnicas destacam-se nessa categoria e abordam, de modo geral, procedimentos e metodologias de avaliação.

A análise dos atos normativos federais evidencia a diversidade de órgãos e instâncias que atuam na regulação e avaliação da educação superior: Ministério da Educação, Conselho Nacional da Educação, INEP e a Comissão Nacional de Avaliação da Educação Superior. Cabe mencionar ainda a Comissão Técnica de Acompanhamento da Avaliação (CTAA), extinta pelo Decreto $n^{\circ}$ 9.759, de 11 de abril de 2019, mas recriada pela Portaria $n^{\circ}$ 96, de 22 de janeiro de 2020. Fica demonstrada, também, a multiplicidade de normas publicadas para regulamentar a área, no contexto da Nova Gestão Pública na educação superior brasileira.

A reorganização interna do MEC, em 2011, ao criar a Seres, colaborou de forma efetiva para esse processo, centralizando as atividades regulatórias, antes dispersas entre três secretarias, na busca por maior eficiência, num processo que se mostrava de bastante complexo e com dificuldades de gerenciamento. Observou-se, no entanto, que apesar de a Seres ser responsável pela regulação e a supervisão, suas ações foram encaminhadas de tal forma, que resultaram no estabelecimento da subordinação da avaliação à regulação.

A concepção contida na proposta de criação do Insaes é esclarecedora a esse respeito pois, além da formulação e execução de ações de supervisão e avaliação de cursos e instituições, o Insaes teria sob sua responsabilidade a autorização, reconhecimento e renovação de 
reconhecimento de cursos e o credenciamento e recredenciamento de IES; realização de avaliações in loco; gestão de sistema público de informações cadastrais de IES, docentes e discentes. A responsabilidade de coordenar o processo de avaliação dos cursos de graduação, constante do inciso VI do artigo $1^{\circ}$ da Lei $\mathrm{n}^{\circ}$ 9.448, de 1997, que transformou o INEP em autarquia federal seria revogada pelo Projeto de Lei $n^{\circ}$ 4372/2012.

Esta proposta foi objeto de considerações da Conaes, por meio de ofício datado de 17 de outubro de 2013 (BRASIL, 2013). Entre outros aspectos, a comissão criticou a intenção de realizar avaliação, supervisão e regulação da educação superior no âmbito de uma mesma instância, por ser a regulação uma entre as consequências dos processos avaliativos, desenvolvidos para orientar decisões referentes à regulação e ao estabelecimento de políticas públicas, mas também orientar aos alunos e suas famílias na escolha de opções de estudo e por membros da academia para realizar melhorias nos cursos e na instituição. Fundamentada em procedimentos e na literatura internacional, a Conaes afirma que a regulação pode ser entendida como uma política de governo, ajustada em função de políticas e de garantia de padrões mínimos de qualidade, enquanto a avaliação deve ser entendida como uma política de Estado, fundamentada numa concepção de qualidade e baseada em noções técnicas protegidas de interferência de natureza política ou imediata. Como conclusão do documento, a Conaes afirma ser imprescindível que os processos de avaliação fossem desenvolvidos no interior do Insaes de modo independente dos de supervisão e regulação.

\section{Considerações finais}

Neste artigo, foram analisados os atos normativos publicados no período compreendido entre 2001 e 2019, referentes à regulação, à supervisão e à avaliação, concebendo-os como resultado das mudanças que se deram no papel do Estado e na concepção de avaliação e regulação, refletindo a atuação do Estado brasileiro no campo da educação superior. A grande quantidade de atos editados deixa evidente a fragmentação das normas que regulam esse campo, em determinadas situações proporcionando até mesmo insegurança na interpretação e aplicação. Em consequência, tanto o pessoal incumbido do cumprimento das normas quanto os pesquisadores da temática, são levados a consultar diversos atos para poder interpretar as normas vigentes. Em especial, deve ser destacada a abrangência adquirida pela publicação de notas técnicas, que embora tenha ocorrido em um período menor, não deixou de ser importante instrumento para assegurar maior agilidade às ações de regulação da educação superior.

É importante ressaltar, ainda, que a adoção de grande parte dos instrumentos normativos se faz de forma privilegiada pelo Poder Público, cuja validade depende da decisão dos órgãos 
governamentais e de seus dirigentes, sem consultas públicas quanto à sua pertinência e efetividade para as instituições de educação superior. Estes movimentos podem ser observados tanto em relação às normativas da avaliação quanto da regulação da educação superior.

O fato de os atos normativos serem em sua maioria elaborados sem consultas públicas, no entanto, não significa que não traduzam interesses dos diferentes setores do campo da educação superior brasileira. Como resultado da execução de políticas públicas, esses atos revelam as prioridades da agenda governamental e as estratégias escolhidas para atingi-las, nas quais pode ser identificada a atenção dada a interesses de diversas ordens manifestados por esses setores.

Isso remete à análise sobre a regulação feita por Barroso (2005). Apesar de no sistema público de ensino o Estado ser a fonte essencial de regulação, ele está sujeito a múltiplas e até contraditórias regulações, tornando imprevisível o efeito das regulações por ele desencadeadas. Por essa razão, diz o autor, mais do que a regulação, é a multirregulação a determinante das alterações sobre as ações que garantem o funcionamento do sistema educativo. Os ajustamentos e reajustamentos a que os processos de regulação dão lugar "não resultam de um imperativo qualquer, político, ideológico e ético definido a priori, mas sim dos interesses, estratégias e lógicas de ação de diferentes grupos de atores por meio de processos de confrontação, negociação e recomposição de objetivos e poderes" (2005 p.734). O modo como isso se configura nos atos analisados é tema para análises mais aprofundadas.

Sem dúvida, os atos normativos se configuram na ação do Estado e demonstram momentos históricos de hegemonia na concepção de educação superior, na forma de ações de regulação e avaliação. No período analisado, é perceptível a existência de normas que tanto partem do pressuposto da avaliação como processo formativo e emancipatório quanto como processo com ênfase em resultados e subordinado ao controle e à regulação. No contexto da NGP, cada vez mais, é o último modelo que prevalece.

\section{Referências}

BARROSO, João. O estado, a educação e a regulação das políticas públicas. Educação \& Sociedade, Campinas, v. 26, n. 92, p. 725-751, out. 2005. Disponível em http://www.cedes.unicamp.br. Acesso em: 20 out. 2020.

BARROSO, João; CARVALHO, Luís Miguel. Apontamentos sobre os "novos modos de regulação" à luz de estudos sobre as relações entre conhecimento e política. Propuesta

Educativa, Buenos Aires, v. 2, n. 36, ano 20, p. 9-24, nov. 2011. Disponível em https://www.redalyc.org/pdf/4030/403041707003.pdf. Acesso em: 20 out. 2020.

BRASIL. Constituição da República Federativa do Brasil. Diário Oficial da República Federativa do Brasil, Brasília, 5 out. 1988. 
BRASIL. Lei n ${ }^{\circ}$ 9.394, de 20 de dezembro de 1996. Estabelece as Diretrizes e Bases da Educação Nacional. Diário Oficial da República Federativa do Brasil, Brasília, 23 dez. 1996. Seção 1, p. 27833.

BRASIL. Lei $\mathbf{n}^{\mathbf{0}}$. 10.172, de 9 de janeiro de 2001. Aprova o Plano Nacional de Educação e dá outras providências. Brasília, 2001. Disponível em:

http://www.planalto.gov.br/ccivil_03/leis/leis_2001/110172.htm. Acesso em: 10 abr. 2020.

BRASIL. Decreto n ${ }^{0}$ 3.860, de 9 de julho de 2001. Dispõe sobre a organização do ensino superior, a avaliação de cursos e instituições, e dá outras providências. Brasília, 2001.

Disponível em: http://www.planalto.gov.br/ccivil_03/decreto/2001/D3860.htm Acesso em: 7 out. 2020.

BRASIL. Lei ${ }^{\circ}$ 10.861, de 14 de abril de 2004. Institui o Sistema Nacional de Avaliação da Educação Superior. Brasília, 2004. Disponível em:

http://www.planalto.gov.br/ccivil_03/_ato2004-2006/2004/lei/110.861.htm Acesso em: 15 abr. 2020.

BRASIL. Decreto $n^{0} 5.773$ de 9 de maio de 2006. Dispõe sobre o exercício das funções de regulação, supervisão e avaliação de instituições de educação superior e cursos superiores de graduação e sequenciais no sistema federal de ensino. Brasília, 2006. Disponível em: http://portal.mec.gov.br/seed/arquivos/pdf/legislacao/decreton57731.pdf. Acesso em: 15 jun. 2020.

BRASIL. Portaria Normativa n. ${ }^{\circ}$ 40, de 12 de dezembro de 2007, republicada em 29 de dezembro de 2010. Institui o e-MEC, sistema eletrônico de fluxo de trabalho e gerenciamento de informações relativas aos processos de regulação, avaliação e supervisão da educação superior no sistema federal de educação, e o Cadastro e-MEC de Instituições e Cursos Superiores e consolida disposições sobre indicadores de qualidade, banco de avaliadores (Basis) e o Exame Nacional de Desempenho de Estudantes (ENADE) e outras disposições. Brasil, 2010. Disponível em:

http://portal.mec.gov.br/index.php?option=com_docman\&view=download\&alias=16763port-norm-040-2007-seres\&Itemid=30192 Acesso em: 7 out. 2020.

BRASIL. Projeto de Lei no 4.372/2012. Cria o Instituto Nacional de Supervisão e Avaliação da Educação Superior - INSAES, e dá outras providências. Brasília, 31 ago. 2012. Disponível em: https://www.camara.leg.br/proposicoesWeb/fichadetramitacao?idProposicao=554202. Acesso em: 7 out. 2020.

BRASIL. Comissão Nacional de Avaliação da Educação Superior. Ofício no 77/2013/CONAES/GM/MEC. Brasília, DF: Ministério da Educação, 17. out. 2013. Disponível em: http://portal.mec.gov.br/index.php?option=com_docman\&view=download\&alias $=14425$ ponderacoes-pl4372-insaes-2013-pdf\&category_slug=outubro-2013-pdf\&Itemid=30192. Acesso em: 9 out. 2020.

BRASIL. Decreto n⿳ 9.235, de 15 de dezembro de 2017. Dispõe sobre o exercício das funções de regulação, supervisão e avaliação das instituições de educação superior e dos cursos superiores de graduação e de pós-graduação no sistema federal de ensino. Brasília, 2017a. Disponível em: http://www.planalto.gov.br/ccivil_03/_ato20152018/2017/decreto/D9235.htm. Acesso em: 14 abr. 2020.

BRASIL. Congresso Nacional. Manual de redação: padronização e documentos administrativos. Brasília: Câmara dos Deputados, 2017b. Disponível em: http://biblioteca2.senado.gov.br:8991/F/CSKTH6AY4Q3LJHN5AXJA6VHCQD2VNRBY99 
NCEFFIL8NCHX9VXB-48003?func=full-setset\&set_number=007304\&set_entry=000001\&format=999. Acesso em: 17 jul. 2020.

BRASIL. Decreto desburocratiza e premia instituições pela qualidade. 2017c. Disponível em: http://portal.mec.gov.br/ultimas-noticias/212-educacao-superior-1690610854/58611decreto-desburocratiza-e-premia-instituicoes-pela-qualidade. Acesso em: 01 out. 2020.

BRASIL. Decreto $\mathbf{n}^{0} \mathbf{1 0 . 1 3 9}$, de 28 de novembro de 2019. Dispõe sobre a revisão e a consolidação dos atos normativos inferiores a Decreto. 2019. Disponível em:

http://www.planalto.gov.br/ccivil_03/_ato2019-2022/2019/decreto/D10139.htm. Acesso em: 14 abr. 2020.

ROGERS, David. Portaria. In: Enciclopédia Jurídica. Hong Kong, 2020. Disponível em http://www.enciclopedia-juridica.com/pt/d/portaria/portaria.htm Edição 2020. Acesso em: 9 jun. 2020

NEWMAN, Janet; CLARKE, John. Gerencialismo. Educação e Realidade, Porto Alegre, v. 37, n. 2, p. 353-381, maio/ago. 2012. Disponível em: http://www.ufrgs.br/edu_realidade. Acesso em: 20 out. 2020.

VERGER, Antoni; NORMAND, Romuald. Nueva gestión pública y educación: elementos teóricos y conceptuales para el estudio de un modelo de reforma educativa global.

Apresentação. Educação e Sociedade, Campinas, v. 36 n. 132, p. 599-622, jul./set. 2015. 